\title{
Sociedade da informação e reestruturação produtiva: crítica à dimensão utilitarista do conhecimento
}

\author{
The information society and the restructuring of production: \\ a critique of the utilitarian dimension of knowledge
}

Elisabete Gonçalves SOUZA'

\section{Resumo}

Discute os conceitos, sociedade da informação e sociedade do conhecimento, tomando como referencial analítico os imperativos impostos pela reestruturação produtiva do capital ao mundo do trabalho e da produção. Objetiva mostrar como, sob a ótica neoliberal, questões como acesso à informação e à produção de conhecimentos são tratadas de forma estreita, em que persiste a ênfase à dimensão utilitarista da informação e do conhecimento, subordinada à lógica econômica, cujo foco é o aumento da produtividade e a competitividade das organizações em detrimento da formação integral do trabalhador. Tem como referencial teórico as discussões trazidas por autores preocupados em desmistificar o propagado determinismo tecnológico, proporcionado pelas Tecnologias de Informação e Comunicação, ressaltando o papel da educação, em sentido lato, e da ciência da informação, em sentido estrito, nos debates acerca da democratização do acesso; do domínio dos conteúdos informacionais para além da sua dimensão utilitarista. Concluiu que a falta de domínio sobre os processos técnicos e científicos está intimamente relacionada à visão utilitarista do conhecimento propagado pela pedagogia das competências. No campo econômico, especialmente para os países não produtores de tecnologia, o abandono da teoria em favor da prática se expressa nas ações pragmáticas que marcam as relações cotidianas e o mundo do trabalho; na supervalorização do trabalhador multifuncional, em detrimento da sua formação integral (técnico-científica e humanista).

Palavras-chave: Conhecimento. Educação. Informação. Tecnologia.

\begin{abstract}
The paper discusses the concepts of the information society and knowledge society taking as an analytical framework the constraints imposed by the productive restructuring of capital on the world of work and production. It aims to show how, under a perspective of new liberalism, issues such as access to information and to the production of knowledge in the strict sense of the phrase, which continues to emphasize the utilitarian dimension of information and knowledge, subject to economic logic, which focuses on increasing productivity and competitiveness of organizations at the expense of not fully training the workers. Its theoretical point of reference are the discussions introduced by authors concerned with demystifying the spread of technological determinism offered by information and communication technology, emphasizing the role of education in its broadest sense and information science in its strictest sense, in the debates over the democratization of access, the dominion of informational content beyond the utilitarian dimension. The conclusion is that the lack of mastery over the technical and scientific processes is closely related to the utilitarian view of knowledge propagated by skills teaching. In the economic domain, especially for those countries that are not producers of technology, the abandonment of theory in favor of practice is expressed in the pragmatic actions that mark everyday relationships and the world of work; in the overvaluation of the multifunctional worker, to the detriment of theirfull training (technical/scientific and humanistic).
\end{abstract}

Keywords: Knowledge. Education. Information. Technology.

\footnotetext{
1 Professora, Universidade Federal Fluminense, Departamento de Ciência da Informação. R. Profa. Lara Vilela, 126, São Domingues, 24210-590, Niterói, RJ, Brasil. E-mail: <elisagon@ig.com.br>.
}

Recebido em 24/3/2011 e aceito para publicação em 4/8/2011. 


\section{Introdução}

A informatização é o traço característico do debate público sobre o desenvolvimento desde o final do século $X X$, período em que o capitalismo, face à globalização da economia e das comunicações, assume-se neoliberal. Nesse cenário, as expressões "sociedade de informação"e "sociedade do conhecimento" são associadas a temas como competitividade, produtividade, empregabilidade, entre outros.

Esse tipo de abordagem esvazia o debate em torno da democratização do acesso à informação e à produção de conhecimentos, reduzindo a questão à lógica econômica estritamente privada e guiada pela ênfase nas habilidades e competências para a empregabilidade. Nessa perspectiva, os sujeitos, de acordo com a posição que ocupam na estrutura social, são reduzidos à condição de consumidores de um quantum de informação e de conhecimentos necessários à produção e reprodução de suas condições materiais de sobrevivência, o que significa dizer que, sob a égide neoliberal, a sociedade da informação e do conhecimento, apesar de universalizada graças às novas tecnologias, não é a mesma para todos. Ou seja: aqueles que têm acesso à informação e ao conhecimento têm mais possibilidades de aprender, de se desenvolver (como pessoa e cidadão) do que aqueles que são excluídos desses bens ou apenas deles se aproximam de forma tênue, sendo um dos maiores impedimentos, em nosso país, a fragilidade do acesso à cultura eà educação, em especial à educação escolar.

São estas questões que esse artigo pretende abordar, sem, contudo, ter a pretensão de oferecer respostas, mas sim de promover um convite à reflexão, no sentido de discutir a tão propagada democratização da informação e do conhecimento face às intencionalidades da reestruturação produtiva do capital; objetiva desmistificar o propagado determinismo tecnológico proporcionada pelas Tecnologias de Informação e Comunicação (TIC), ressaltando o papel das unidades de informação, como as bibliotecas, os arquivos, etc. e de seus intelectuais, nos debates acerca da democratização do acesso; do domínio dos conteúdos informacionais para além da sua dimensão utilitarista, subordinada à lógica estreita do mercado.

Nessa perspectiva discute-se, que a produção de conhecimentos depende da mobilização de conheci- mentos anteriores, da valorização do itinerário cultural e formativo dos sujeitos, e que o domínio da informação e dos conhecimentos proporcionados pelo acesso às TIC, não deve ser entendido apenas como instrumento de competitividade, mas como estratégia de capacitação dos indivíduos, de modo que possam se apropriar das "mudanças técnicas em prol do pleno exercício de sua cidadania" (Lemos, 1999, p.25).

Partindo da crítica à apropriação privada de informações, saberes e conhecimentos, busca-se discutir a universalização e a publicização do conhecimento, entendido aqui como patrimônio cultural da humanidade, "elemento indispensável ao desenvolvimento humano, em suas múltiplas dimensões" (Lemes, 1999, p.25). Para tanto, este estudo é iniciado, fazendo a crítica à razão instrumental, à subordinação do conhecimento à lógica do capital em detrimento da busca (no sentido político) da formação integral dos cidadãos e de seu impacto nas relações sociais de produção.

O conceito "razão instrumental" que norteia as análises feitas neste artigo partiu das reflexões feitas por Gamboa (1997) e Goergen (2003) e relaciona-se com o "sentido prático e útil do conhecimento, identificado como socialmente relevante e, por isso, incontestável, uma vez que dele nasce o chamado progresso" (Goergen, 2003, p.12). Por isso, criticar este sentido instrumental do conhecimento é tarefa difícil, pois todos apreciam sobremodo os benefícios trazidos pelos avanços da ciência e da tecnologia. De acordo com o autor, essas vantagens ofuscam efeitos perversos que tal racionalidade abriga: como o exercício do poder, da dominação, que emergem do uso privado do conhecimento por parte daqueles que dele se apropriam e, explorando consequentemente seu potencial utilitarista, geram domínio, dependência, exclusão e destruição.

Avança-se discutindo a relação entre as novas tecnologias de informação e comunicação e as transformações no mundo do trabalho; as exigências impostas pelos setores produtivos de mais conhecimentos e habilidades específicas por parte dos trabalhadores e a contradição que tal discurso engendra. Como ressalta Kuenzer e Deluiz (2005), os conhecimentos básicos, tanto no plano dos instrumentos necessários para o domínio da ciência, da cultura e das formas de comunicação, como no plano dos conhecimentos científicos e tecnológicos presentes 
no mundo do trabalho e nas relações sociais contemporâneas, exigem do Estado e da sociedade investimento em educação sistemática e continuada. A partir dessa perspectiva faz-se uma crítica à educação funcional calcada nas habilidades e competências para a produtividade em detrimento da busca de conhecimentos inovadores, que garantam, para o indivíduo em particular e para a sociedade brasileira de modo geral, um desenvolvimento autônomo. Nesse contexto, ressalta-se ainda a função social das bibliotecas e o papel destas na democratização do acesso à informação.

\section{Sociedade da informação e do conhecimento: limites e possibilidades}

No bojo da reestruturação produtiva do capital, as novas tecnologias de informação e comunicação surgem como instrumentos possibilitadores da globalização. Segundo Franco (2005, p.2):

[...] a aceleração da comunicação dos conhecimentos produzidos transforma os conhecimentos técnicos e científicos nas principais fontes de produtividade, gerando assim um grau de exclusão social, econômica e intelectual cada vez mais acentuado, por excluir aqueles que não conseguem acompanhar o ritmo, mantendo-os marginalizados deste processo.

A aceleração dos processos de comunicação ao mesmo tempo em que permite a democratização do saber também dissemina valores culturais e de mercado impostos pelas culturas hegemônicas, dificultando, assim, uma reflexão crítica sobre uso da informação. Isso acontece quando o conhecimento veiculado pelas novas tecnologias torna o seu usuário um mero reprodutor dos discursos difundidos. Nesse caso o fato de ter acesso às novas mídias - Internet, base de dados, bibliotecas digitais, etc. - não faz do usuário um sujeito capaz de gerar novos conhecimentos. Ou seja, ter acesso às novas tecnologias, saber usar computadores e Internet, não significa que o sujeito tenha domínio destas ferramentas, que saiba explorar suas potencialidades, produzir novos conhecimentos. Para Santos et al. (2008, p.210):

[...] a era da informação e do conhecimento se caracteriza pela superação das barreiras temporais e territoriais através da globalização. Os indivíduos têm seus relacionamentos reconfigurados por uma rede de proporções mundiais.
A sobrevivência nesse cenário requer aptidão e o desenvolvimento de habilidades paraqueo indivíduo seja capaz de acessar, compreender efazer o melhor uso das informações disponiveis (grifos meu).

Ampliando as reflexões dos autores acima citados, é importante ressaltar que, se as políticas públicas de disseminação das novas tecnologias de informação e comunicação se preocupam mais com a questão do acesso, cabe às unidades de informação organizar e disponibilizar para todos os cidadãos os diferentes conteúdos informacionais, assim como cabe à sociedade, em especial à escola, preparar os indivíduos para análise crítica dos conteúdos, para que, partindo de dados e informações, se possa produzir novos conhecimentos, para uso individual e coletivo. Esse sim seria o sentido pleno da expressão "sociedade da informação e do conhecimento".

Para Werthein (2006), a expressão sociedade da informação passou a ser utilizada, nos últimos anos do século passado, como substituto para o conceito complexo de sociedade pós-industrial e como forma de transmitir o conteúdo específico do novo paradigma técnico-econômico que se expressa nas transformações técnicas, organizacionais e administrativas que têm como fator-chave os insumos de informação propiciados pelos avanços tecnológicos nas áreas de microeletrônica e telecomunicações. Esta sociedade pós-industrial ou informacional, como se refere Castells (2000), está ligada à expansão e à reestruturação do capitalismo; às novas tecnologias e ao paradigma da flexibilidade na organização produtiva, o que vem permitindo ao "sistema capital" (Meszáros, 2002) realizar com rapidez e eficiência todos os processos de sua cadeia produtiva, provocando, em termos da organização do trabalho desregulamentação, privatização e ruptura do modelo de contrato social entre capital e trabalho característico do capitalismo industrial (Antunes, 2000).

Esse novo paradigma tem, segundo Castells, as seguintes características: a informação é sua matéria-prima: diferente do passado cujo foco era a utilização da informação para agir sobre a tecnologia (máquinas simples) hoje se desenvolvem tecnologias (softwares) que permitem o homem atuar sobre a informação, acessando e selecionando informações de acordo com seus interesses individuais e/ou profissionais. Sob esse aspecto pode-se dizer que a informação tornou-se parte integrante 
de toda atividade humana, individual ou coletiva e, portanto, todas essas atividades tendem a ser afetadas diretamente pelas novas tecnologias informacionais; redes de informação que favorecem as trocas de dados $e$ conteúdos em tempo real através de infovias abertas (Internet) ou seletivas (Intranets); flexibilidade: a tecnologia favorece processos reversíveis, permite modificação por reorganização de componentes e tem alta capacidade de reconfiguração; a convergência de tecnologias: a aproximação entre a microeletrônica, as telecomunicações e as diferentes áreas do saber, como a ciência da informação.

Essa versatilidade das TIC e sua aplicação em inúmeros campos da ciência e da cultura podem alimentar a visão ingênua de determinismo tecnológico, segundo a qual as transformações em direção à sociedade da informação resultam da tecnologia, como se esta seguisse uma lógica técnica e, portanto, neutra, ou seja, fora da interferência de fatores sociais e políticos (Demo, 1999). No entanto, o que ocorre é o inverso: a tecnologia resulta de uma interação complexa, em que fatores sociais préexistentes, como as condições para a pesquisa científica, somam-se a outros, como a criatividade, o espírito empreendedor, o mercado. Na atual conjuntura, a mola mestra que impulsiona tais fatores é a competitividade econômica baseada na produção e uso intensivo de conhecimento, que geram novos produtos e serviços que garantem a reprodução ampliada do capital. Pode-se dizer que, no paradigma neoliberal informação e conhecimento são os principais fatores de produção, o que vem implicando numa reorganização das relações sociais, de trabalho.

No bojo desta discussão"surge a necessidade do desenvolvimento de novas competências que tornem as pessoas capazes de lidar com o construto informação" (Santos et al., 2008, p.210). O que significa saber buscar, selecionar, avaliar e analisar informações de modo a poder usá-las na construção de novos conhecimentos. No entanto, no âmbito organizacional, em especial em países de capitalismo tardio, as competências se restringem à dimensão pragmática, o que é necessário à produtividade da empresa, em geral, e do trabalhador, em particular. Nesse contexto, opta-se (governos e empresas) pela transferência de tecnologias e pelo treinamento em detrimento da qualificação contínua dos trabalhadores.
No entanto, a busca do desenvolvimento econômico autônomo, implica, como ressalta Lemos (1999), em uma forte demanda por capacitação para responder às necessidades e oportunidades que se abrem. Capacitação esta que deve demandar por parte dos trabalhadores uma sólida educação básica inicial, complementada por processos educativos que integrem, em todo o percurso formativo, conhecimento básico, conhecimento específico e conhecimento sócio-histórico, ou seja, ciência, tecnologia e cultura, pois a nova base técnica do capital, pautada na microeletrônica, exige que "o conhecimento passe a se dar também sobre os processos, e não mais apenas sobre os produtos" (Kuenzer, 2005, p.34). Esse cenário exige dos setores público e privado investimentos em pesquisa e educação, de modo que os instrumentos disponibilizados pelo desenvolvimento das tecnologias de informação e comunicação não sejam inúteis pelo fato de "não existir uma base de indivíduos capacitados para utilizá-los, para acessar as informações disponíveis e transformá-las em conhecimento e inovação" (Lemos, 1999. p.129).

No entanto, esse processo não é fácil. De acordo com a autora há um caráter localizado da inovação e do conhecimento, uma distribuição espacial desigual da capacidade de geração e de difusão de inovações, ocorrendo uma significativa "concentração em nível mundial da taxa de introdução de inovações, com algumas regiões, setores e empresas tendendo a desempenhar o papel de principais indutores de inovações, enquanto outras parecem ser relegadas ao papel de adotantes" (Lemos, 1999, p.137).

Para os países em desenvolvimento, a modernização de estruturas industriais tradicionalmente existentes não deve se limitar à aquisição de tecnologias por meio da sua compra, mas investir no seu desenvolvimento. Pois a ciência e a tecnologia não são facilmente transferidas nem comparadas.

Pode-se transferir ou comprar os conhecimentos codificados, mas não os tácitos e sem estes, não se tem a chave para a decodificação dos conhecimentos adquiridos como tecnologia. Nesse sentido, reforça-se a importância dos investimentos em capacitação, pesquisa e desenvolvimento e em particular do aprendizado, paralelamente à importação de tecnologia, para que seja possível o desenvolvimento tecnológico endógeno (Lemos, 1999, p.142). 
Nessa perspectiva, para países em desenvolvimento como o Brasil, é necessário que se reconheça, primeiramente, a importância da inovação "tecnologia" (produção de Know-how), de modo a capacitar o país a acompanhar as mudanças em curso, no sentido de se apropriar daquilo que tem de mais avançado em termos tecnológicos, sob o atual modo de produção capitalista e inverter isto, em prol do desenvolvimento de um novo projeto de sociedade, onde os esforços para o desenvolvimento econômico devem se voltar para as especificidades locais.

Daí a importância de se redimensionar a definição de inovação, observando que, para os países periféricos, o conceito é minimizado, significando apropriação de conhecimentos através da transferência ou compra de tecnologias geradas em países centrais, do que incentivo à geração de novos conhecimentos que expressem as necessidades de desenvolvimento da economia, das instituições e da sociedade de forma geral.

No item que segue, relacionaremos os conceitos de sociedade da informação e do conhecimento com os de produtividade e competitividade, tomando como referência o grau de desenvolvimento econômico alcançado pelos diferentes países, de modo a mostrar que o acesso e o domínio da informação, no sentido da produção de novos conhecimentos (culturais, artísticos, científicos e tecnológicos) dependem do Estado, enquanto garantidor de direitos sociais fundamentais: como o direito à informação e à educação.

\section{As diferentes sociedades da informação: 0 acesso à informação nos países centrais e nos periféricos}

Para termos uma noção de como informação e conhecimento são fatores de produção, alguns dados quantitativos são esclarecedores. Na produção de um carro, por exemplo, por mais que seja sofisticado seu design, a matéria-prima corresponde ainda a 35\% do custo, sendo a mão-de-obra responsável por 15\% do custo, os restantes 50\% correspondem à ciência ou ao investimento em conhecimento. De acordo com Demo (1999), em termos teóricos, estamos vivendo a era da mais-valia relativa como assinalava Marx, fundada na ciência e tecnologia, ou seja, a produtividade econômica é alimentada essencialmente, não mais pela força física do trabalhador, mas por sua inteligência, objetivada nas novas tecnologias incorporadas à produção. Contudo, tais análises devem ser relativizadas para não incorrermos no indevido "determinismo tecnológico" já que a "sociedade da informação" não é igual para todos, países e pessoas. Nessa perspectiva, como alerta Agudo Guevara (2000), melhor seria a ela nos referirmos como"sociedades da informação"no plural para identificar, numa dimensão local, aquelas nas quais as novas tecnologias e outros processos sociais provocaram mudanças paradigmáticas.

Em vista do exposto, pode-se dizer que o determinismo tecnológico e o evolucionismo - a compreensão da sociedade da informação como uma etapa do desenvolvimento capitalista - distorce a análise do complexo processo de mudança social que envolve o novo paradigma. Tais posturas impedem ou ignoram o papel ativo que a sociedade, o capital e o Estado, têm desempenhado no decorrer da história, tanto para promover quanto para sufocar o desenvolvimento tecnológico e suas aplicações sociais. Isso é particularmente claro no que se refere às novas tecnologias. O avanço tecnológico no novo paradigma foi em grande parte o resultado da ação do Estado associado ao capital, estando o primeiro - o Estado - à frente de iniciativas que visam ao desenvolvimento da "sociedade da informação" nas nações centrais, industrializadas, e naquelas que participam de forma subordinada da divisão do trabalho internacional, os chamados países em desenvolvimento ou semiperiféricos, como o Brasil.

Partindo das reflexões trazidas por Werthein (2006), um olhar sobre a experiência concreta das sociedades contemporâneas permite revelar como a reestruturação do capitalismo e a difusão das novas tecnologias da informação está interagindo com as forças sociais locais e gerando um processo de transformação social. Tal processo atinge níveis díspares nas várias sociedades, e ao lado da expressão "sociedade da informação" são encontradas outras como países ou grupos sociais "ricos em informação"e "pobres em informação". Tais expressões são reflexos das desigualdades de renda e de desenvolvimento industrial entre os povos e classes sociais. Enquanto, no mundo industrializado, grande parte da população pode usufruir da informatização, os países em desenvolvimento, entre eles os latino-americanos, ainda têm que incorporar vastos setores da população, adultos, 
jovens e crianças das classes trabalhadoras no campo e na cidade, além das populações marginalizadas, como os desempregados crônicos e os "sem-teto", que engrossam as fileiras daqueles que, face ao novo padrão de acumulação produtiva, estão ainda longe de integrar-se ao novo paradigma.

De acordo com o levantamento feito por Franco (2005), estima-se que cerca de 15\% dos brasileiros têm acesso a um computador e 10\%, à Internet. Desse total, $80 \%$ pertence às classes A e B, e sua localização geográfica concentra-se nas regiões metropolitanas. Dos mais de cinco mil municípios do País, só trezentos contam com infraestrutura essencial para instalação de serviços de acesso à rede, o que tende a deixar de fora da revolução digital 94\% das localidades do País. Esses dados nos apontam as principais condições que interferem no grau de exclusão ao acesso tecnológico: o analfabetismo, a condição socioeconômica e a localização geográfica. Sendo assim, ressalta a autora, a Inclusão 'di-gi-tal', tocar com a ponta dos dedos o universo de informação, é uma realidade para uma pequena parcela da população mundial e, em países como o Brasil, para um público ainda mais seleto. Daí a importância de se incluir a informática como ferramenta pedagógica a auxiliar as atividades didáticas dos professores, assim como a implementação de "tecnologias", como as bibliotecas escolares, espaços raros nas unidades de ensino de educação básica, públicas e privadas, em todo o País.

Nesse contexto, um dos desafios éticos para a constituição das sociedades da informação, desafio que somente a ação social consciente poderá superar, já que certamente não será resolvido pelo avanço tecnológico em si mesmo, nem por uma hipotética evolução natural, mas sim pela construção de um novo projeto societário. Projeto este fundado na ampliação das oportunidades de acesso à informação e ao conhecimento, do qual o Estado neoliberal é o maior tributário, pois se mostrou "mínimo" ou ausente no desenvolvimento de políticas públicas voltadas para a ampliação do capital cultural de nossa população; na garantia do direito à informação, à educação e ao acesso aos bens culturais disponíveis nas bibliotecas, arquivos e museus; na falta de investimentos visando à ampliação dos equipamentos culturais acima mencionados e na restrição da educação básica obrigatória ao mínimo necessário: o ensino fundamental. Tais estreitamentos das políticas públicas no campo cultural e educacional engendraram um tipo de economia da informação coadunada com os interesses do "sistema capital" (Mészáros, 2002) em detrimento da socialização e democratização do conhecimento para todos os cidadãos.

Contraditoriamente, a presença de novas tecnologias de informação e comunicação, como os computadores, a Internet, vêm alijando velhas tecnologias como as bibliotecas, já tão raras na rede pública de educação em todo o país. A ampliação do acesso à informação através de novas tecnologias não vem significando aumento do capital cultural da classe trabalhadora. A massa informacional aumentou, mas a natureza da informação que tem chegado às nossas escolas tem gerado conhecimentos esvaziados de suas bases teóricas, reduzidos à sua dimensão utilitária, o que vem causando uma alienação de novo tipo: a alienação informacional, que gera a desinformação².

Criticar o sentido instrumental do acesso à informação e ao conhecimento é tarefa difícil, face às propagadas vantagens da razão utilitária, expressas em vocativos como"qualificação," "desempenho","competitividade", "produtividade", "empregabilidade", que ofuscam seus efeitos perversos como o exercício do poder, da dominação, que emergem da exploração do conhecimento por parte daqueles que dele se apropriam e, explorando seu potencial utilitarista, geram domínio, dependência, exclusão e destruição (Goergen, 2003).

\section{Sociedade da informação: o triunfo da razão utilitária}

Para Demo (2000), Goergen (2003) entre outros teóricos, a conjugação da sociedade do conhecimento com a lógica abstrata da mercadoria vem se firmando com um discurso hegemônico, levando aqueles que atuam na produção e socialização do conhecimento a abandonar praticamente seu mandato educativo e social,

\footnotetext{
2 Por conta da infovias cotidianamente se é alvo de um bombardeio de informações das quais já não se tem qualquer controle. Na verdade, acha-se que se está informando, mas está desinformando-se, pois o filtro crítico para selecionar esta massa informacional torna-se cada vez mais frouxo, pois se tem tido pouco tempo para se retomar seus fundamentos teóricos. A crítica afastada de seus fundamentos acaba se fragilizando, tornando-se vulnerável aos apelos e do novo contexto comunicativo que vem no esteio do novo paradigma neoliberal.
} 
para restringir-se ao atrelamento capitalista, perfazendo o pano de fundo da competitividade sem limites.

A criatividade está em grande parte aprisionada pelo mercado, provocando forte seletividade nos cursos, em desfavor de compromissos históricos com os interesses coletivos da humanidade. Com efeito, o conhecimento mais inovador é provocado pelo mercado, que necessita do ímpeto desconstrutivo do conhecimento, particularmente do conhecimento dito pós-moderno, colocando a inovação mercantilizada como razão maior de ser (Demo, 2000, p.38).

Neste sentido, ao falarmos de sociedade da informação e do conhecimento é fundamental não perder de vista seu contexto econômico, como já foi ressaltado anteriormente, para que não se supervalorize o aspecto tecnológico, como se essa face do progresso fosse a única. O pano de fundo capitalista revela que não se trata apenas da "sociedade", mas principalmente da "economia" da informação, cujo propósito é facilitar a volatilidade do capital globalizado. Percebe-se assim, que os discursos liberais de "democratização da informação", quando desvelados, mostram-se frágeis, revelando suas contradições: a sociedade da informação e do conhecimento, sob o capitalismo, não será igual para todos, sendo reservada para as classes trabalhadoras sua dimensão pragmática e utilitarista, expressa nas habilidades e competências para a empregabilidade. Trata-se de limites que devem ser superados por aqueles que acreditam num novo modelo societário, em que o acesso à informação e ao conhecimento ultrapassa a lógica instrumental e utilitária e torna-se de fato um direito de todos os cidadãos.

Como ressalta Demo (2000), temos que analisar criticamente os sentidos da sociedade da informação sob a ótica da reestruturação produtiva, no sentido de desmistificar as expectativas ingênuas de que a globalização traria benefícios repartidos com todos globalmente.

As pretensões'universalizantes' do conhecimento, tão bem expressas na ideia de 'universidade', redundaram no aprisionamento ostensivo de suas energias no mercado, assinalando que o efeito redistributivo é, como regra, inverso. O mundo tornou-se uma'pequena aldeia', não tanto porque nos vemos e comunicamos mais facilmente, mas porque as linhas de força se fizeram tanto mais convergentes [...]. De uma parte, a interdepen- dência dos povos e pessoas pode repercutir em graus maiores de liberdade, à medida que todos estamos no mesmo barco, mas, de outra, pode produzir amarras ainda mais rígidas, quando sua dinâmica foge ao controle da maioria, concentrando-se, como privilégio extremo, em poucas mãos (Demo, 2000, p.38).

Nesse contexto, ter consciência da desinformação será, portanto, parte fundamental do processo de busca da informação, numa perspectiva emancipadora, quiçá transformadora, do atual processo societário, no sentido em que os trabalhadores possam ser vistos não só como consumidores de informação, e de um quantum de conhecimento necessário à reprodução das relações de produção, mas como sujeitos autônomos, capazes de buscar a informação, assim como: selecioná-la, avaliá-la e transformá-la em novos conhecimentos.

Sem precisar recorrer a formulações utópicas representadas pelas especulações de (Werthein, 2006, p.74) para quem "a tecnologia dos computadores terá como função fundamental substituir e ampliar o trabalho mental dos homens", reconhece-se que muitas das promessas do novo paradigma tecnológico foram e estão sendo realizadas, particularmente no campo das aplicações das novas tecnologias à educação, através da educação a distância, bibliotecas digitais, etc. No entanto, o contexto econômico no qual está inscrita a sociedade da informação nos permite elaborar o seguinte pressuposto: por mais fabulosas que sejam as possibilidades de acesso à informação e ao conhecimento, estes não são distribuídos equitativamente para todos, pois sofrem os limites impostos pelo sistema-capital, cuja natureza se firma na desigualdade no campo econômico e cultural, que se expressa no campo político entre dominantes e dominados, o que leva a relativizar os benefícios que a sociedade da informação e do conhecimento pode oferece às perspectivas de avanços significativos para a vida individual e coletiva.

\section{Considerações Finais}

O desenvolvimento, seja de um indivíduo e/ou de uma nação, está diretamente relacionado ao pleno acesso à informação e à educação, visando à produção de conhecimentos com autonomia e reflexão crítica nos campos científico, tecnológico, cultural e artístico. A falta 
de domínio sobre os processos técnicos e científicos está intimamente relacionada à visão utilitarista do conhecimento propagada pela pedagogia liberal, em que se destaca a busca de habilidades e competência, visando à produtividade e a competividade. Contudo, a contradição entre o lado mocinho e bandido do modelo de racionalidade deve ser superada ou, pelo menos, minimizada o quanto possível.

Tal postura traz sérias implicações no modo como nossas vidas são produzidas. No campo político seu reflexo aparece nas formas individualizadas em que os sujeitos vêm conduzindo suas reivindicações, seus direitos. No campo educacional, especialmente para os países não produtores de tecnologia e ciência, o abandono da teoria em favor da prática se expressa nas relações cotidianas e no mundo do trabalho, onde as organizações empresariais optam pela qualificação dos trabalhadores centrais em detrimento da desespecialização do trabalho produtivo industrial, gerando uma massa de trabalhadores multifuncionais, com largo domínio do trabalho operacional, com escolaridade suficiente para se qualificarem continuamente, individualmente competitivos e, para tanto, despolitizados.

\section{Referências}

AGUDO GUEVARA, A. Etica en la sociedad de la informacion: reflexiones desde America Latina. In: SEMINARIO INFOETICA, 2000, Rio de Janeiro. Anais... [S.I: s.n., 2000?].

ANTUNES, R. Os sentidos do trabalho: ensaio sobre a afirmação e a negação do trabalho. São Paulo: Bomtempo, 2000.

CASTELLS, M. A era da informação: economia, sociedade e cultura. In: CASTELLS, M. A sociedade em rede. São Paulo: Paz e Terra, 2000.

DEMO, P. Conhecimento moderno: sobre ética e intervenção do conhecimento. 2.ed. Petrópolis, RJ: Vozes, 1999.

DEMO, P. Ambivalências do conhecimento e da vida. Ciência da Informação, v.29, n.2, p.37-42, 2000. Disponível em: <http:// www.scielo.br>. Acesso em: 10 abr. 2009.

FRANCO, M.G. Inclusão digital. 2005. Disponível em: <http:// WWw.educatica.net/participantes/artigo1Monica.php>. Acesso em: 10 maio 2008.
Acredita-se que, numa sociedade de classe, marcada pelas desigualdades, instituições como as bibliotecas podem contribuir para ampliação do capital cultural das pessoas, como podem contribuir para mantê-las na condição de subalternidade, dada a iniquidade nas condições de acesso à informação e ao conhecimento. O papel social da biblioteca está na disseminação da informação no sentido universalista do conhecimento, fruto dos avanços técnico-científicos do homem sobre a natureza. A responsabilidade das bibliotecas, como de outros equipamentos culturais, como as escolas, é criar instrumentos, que possibilitem a comunicação entre as ciências como meio para se tentar compreender a complexidade da realidade, fazendo com que os sujeitos ultrapassem a dimensão fenomenológica.

Dadas as inúmeras contradições que o tema "sociedade da informação e do conhecimento" engendra, cabe não somente aos profissionais da área da informação discuti-lo, mas a toda a sociedade, de modo a se estar atento às artimanhas da teoria neoliberal, ao seu discurso utilitarista do conhecimento e aos seus simulacros de democratização.
GOERGEN, P. Universidade e responsabilidade social. In: LOMBARDI, J.C. (Org.). Temas de pesquisa em educação. Campinas: Autores Associados, 2003

KUENZER, A.; DELUIZ, N. Pedagogia do trabalho na acumulação flexível: os processos de "exclusão includente" e "inclusão excludente" como uma nova forma de dualidade estrutural Entrevista. Boletim Técnico do SENAC, v.31, n.1, p.32-36, 2005. Disponível em: <http://www.senac.br/BTS/311/boltec311c. htm>. Acesso em: 3 fev. 2009.

LEMOS, C. Inovação na era do conhecimento. In: LASTRES, H.M.M.; ALBAGLI, S. (Org.). Informação e globalização na era do conhecimento. Rio de Janeiro: Campus, 1999.

MÉSZÁROS, I. Para além do capital: rumo a uma teoria da transição. Campinas: Unicamp, 2002.

SANTOS, E.M.; DUARTE, E.A.; PRATA, N.V. Cidadania e trabalho na sociedade da informação: uma abordagem baseada na competência informacional. Perspectivas em Ciência da Informação, v.13, n.3, p.208-222, 2008. Disponível em: <http:// www.eci.ufmg.br/pcionline>. Acesso em: 13 abr. 2009.

WERTHEIN, J. A sociedade da informação e seus desafios. Ciência da Informação, v.29, n.2, p.71-77, 2000. Disponível em: <http: www.scielo.br>. Acesso em: 12 mar. 2009. 